\title{
LA MODIFICACIÓN DEL ARTÍCULO 168 DE LA CONSTITUCIÓN ESPAÑOLA A TRAVÉS DEL PROCEDIMIENTO ORDINARIO DE REFORMA
}

JUAN ÁLVAREZ SUÁREZ 


\section{SUMARIO.}

I. INTRODUCCIÓN. II. EL PROCEDIMIENTO AGRAVADO DE REFORMA CONSTITUCIONAL. A. Sobre la revisión total. B. Sobre la revisión parcial: la selección «geográfica» del art. 168. C. Sobre la cláusula de la afectación. III. POSTURAS DOCTRINALES ENFRENTADAS: REFORMA ORDINARIA VS. AUTORREFORMA. A. La tesis de la idoneidad del procedimiento ordinario de reforma para modificar el art. 168 CE. B. Posturas doctrinales en favor de la reforma del art. 168 a través del procedimiento que él mismo establece. IV. UNA APORTACIÓN AL DEBATE. A. La interpretación de la cláusula de la afectación y el respeto a la Constitución. B. Reforma de la Constitución y decisiones constitucionales fundamentales. C. La identificación de las decisiones fundamentales. V. LA VARIACIÓN DEL PROCEDIMIENTO SEGÚN EL TIPO DE REFORMA PROPUESTA. VI. CONCLUSIONES 


\title{
LA MODIFICACIÓN DEL ARTÍCULO 168 DE LA CONSTITUCIÓN ESPAÑOLA A TRAVÉS DEL PROCEDIMIENTO ORDINARIO DE REFORMA
}

\author{
JUAN ÁLVAREZ SUÁREZ \\ Universidad de Oviedo ${ }^{1}$
}

\section{INTRODUCCIÓN}

Después de cuatro décadas de vigencia de la Constitución de 1978, existe una ingente cantidad de literatura académica que ha puesto de manifiesto la necesidad de acometer una reforma constitucional para adaptar su texto a las nuevas realidades sociales, políticas y jurídicas.

Un sector de la doctrina, habida cuenta de que en estas cuatro décadas únicamente se han llevado a cabo dos reformas muy puntuales de la Carta Magna (arts. 13 y 135), ha sostenido que uno de los motivos que explican esa escasa activación del poder de reforma es el relativo a la excesiva rigidez y complejidad de nuestros procedimientos de reforma, especialmente el consagrado en el art. 168. El propio De VEGa García advirtió ya en 1985 que ese precepto parecía estar diseñado para no ser aplicado nunca, y tan solo bastaba el transcurso del tiempo para que se confirmase su aseveración ${ }^{2}$.

Por este motivo, existe un debate clásico entre los constitucionalistas acerca de la modificación del art. $168 \mathrm{CE}$, residiendo las discrepancias en torno al procedimiento adecuado a seguir para reformarlo o suprimirlo.

La existencia de dos procedimientos relativos a la reforma constitucional es una especialidad de nuestro ordenamiento, ya que la rigidez constitucional podría estar

1 Doctorando en Derecho Constitucional. Departamento de Derecho Público. Campus de El Cristo-A, Avenida del Cristo s/n, 33006,Oviedo, Asturias.Email: asuarezj95@gmail.com

2 DE VEGA GARCÍA, Pedro (1985): La reforma constitucional y la problemática del poder constituyente, Madrid, Tecnos, págs. 147-151.

(C) UNED. Revista de Derecho Politico

N. ${ }^{\circ} 108$, mayo-agosto 2020, págs. 219-246 
garantizada únicamente con la existencia del art. $167^{3}$. No obstante, el art. 168, al establecer un procedimiento más gravoso para proceder a una revisión total de la constitución o una revisión parcial que afecte a determinados Títulos o al Capítulo relativo a los derechos fundamentales, pone de manifiesto que el constituyente ha querido dificultar el cambio integral de la Constitución o el de aquellas partes que considera esenciales para la definición de su identidad.

Un elemento que merece la pena señalar es el relativo a la literalidad del art. 168, no figurando él mismo entre los preceptos sustraídos al poder de reforma del art. 167 CE. En consecuencia, a partir de una lectura de nuestra Carta Magna parece posible su reforma a través del procedimiento ordinario.

Es aquí, precisamente, donde reside el debate doctrinal que oscila entre el criterio formalista, que parte de la literalidad, y el criterio no formalista, que considera que para reformar el artículo 168 únicamente cabe respetar los cauces que él mismo establece, ya que de otro modo se produciría un fraude.

Este debate constituye un objeto de estudio con una relevancia jurídica destacada, porque la imposibilidad de actualizar la Constitución está produciendo una sensación de desafección en la ciudadanía y un desgaste del texto constitucional. Además, se puede llegar a otorgar al Tribunal Constitucional (en adelante TC) un poder de reforma encubierto, ya que en ocasiones ha de llevar a cabo interpretaciones manipulativas que se desvían notablemente de la literalidad de los preceptos para evitar declarar la inconstitucionalidad de las leyes aprobadas por el Parlamento. La ausencia de reforma conduce, en la práctica, a «dejar en manos de los tribunales decir cuál es la Constitución», de modo que «la democracia representativa y la soberanía popular se resienten» ${ }^{4}$.

Aunque la rigidez constitucional es importante para lograr la estabilidad y para que la Constitución sea un texto dotado de permanencia en el tiempo, cuando es excesiva "petrifica» indebidamente el texto constitucional, pudiendo derivarse en consecuencia crisis constitucionales. Con la intención de reformar el procedimiento agravado no se busca, no obstante, convertir en flexible a la Constitución española, sino proceder a su simplificación para evitar una petrificación que provoque la obsolescencia normativa, de modo que pueda combinarse la continuidad y permanencia temporal de la Constitución con su revisión y actualización.

Este trabajo, por lo tanto, tiene como objeto examinar cuál pudiera ser el procedimiento adecuado para la reforma del contenido del art. $168 \mathrm{CE}$, y, en particular, si una eventual modificación de dicho precepto pudiera realizarse a través de la técnica procedimental prevista en el art. $167 \mathrm{CE}$.

${ }^{3}$ Constituciones como la italiana (art. 138) o la alemana (art. 79) contemplan un único procedimiento de reforma constitucional.

${ }^{4}$ GARCÍA ROCA, Javier (2017): «De la revisión de las constituciones: constituciones nuevas y viejas», Teoría y Realidad Constitucional, 40, pág. 199. 


\section{EL PROCEDIMIENTO AGRAVADO DE REFORMA CONSTITUCIONAL}

Los caracteres generales del procedimiento de reforma en la Constitución Española han sido enunciados por GARCÍA-EsCUDERO MÁRQUEZ ${ }^{5}$, que destaca el carácter expreso de las reformas, la existencia de múltiples sujetos legitimados para iniciarla, el otorgamiento del poder de reforma a las Cortes y la ausencia de cláusulas de intangibilidad. A estas características añadiremos la configuración del aludido procedimiento doble, que implica la observancia imperativa de un cauce procedimental diferenciado cuando se pretenda modificar alguno de los preceptos constitucionales. En este caso, centraremos nuestra atención en el análisis del art. $168 \mathrm{CE}^{6}$ y la problemática que se deriva de su redacción.

\section{A. Sobre la revisión total}

La reserva procedimental que recoge el artículo 168 CE permite una «revisión total» de nuestra Carta Magna. Sin embargo, existen profundas discrepancias respecto a qué debe entenderse por una revisión total y hay posturas encontradas respecto de la posibilidad de que, efectivamente, esta se separe diametralmente de los elementos básicos que dotan de identidad a nuestro orden constitucional.

Aunque la «revisión total» parecería apuntar a la creación de un texto completamente nuevo, no es menos cierto que una reforma sustancial de partes destacadas de la norma también permitiría hablar de una «revisión total». A modo de ejemplo, podemos plantearnos que una reforma de todos y cada uno de los preceptos no incluidos en la selección del art. 168 supondría más bien una revisión total que, pese a no versar sobre las materias «blindadas», obligaría a optar por el procedimiento agravado.

Para aportar una solución a esta falta de precisión terminológica puede resultar conveniente ahondar en los debates constituyentes. En el informe de la ponencia del Congreso, inicialmente, se explicitaba que podría hablarse de una revisión total «cuando la reforma afect[ase] a un título completo de la Constitución o así lo determin[ase] el Tribunal Constitucional». Como advirtió Laporta SAn Miguel ${ }^{7}$, Alian-

5 GARCÍA-ESCUDERO MÁRQUEZ, Piedad (2007): El procedimiento agravado de reforma de la Constitución de 1978, Madrid, Centro de Estudios Políticos y Constitucionales, págs. 7-10.

${ }^{6}$ Art. 168 CE: 1. Cuando se propusiere la revisión total de la Constitución o una parcial que afecte al Titulo preliminar, al Capítulo segundo, Sección primera del Título I, o al Título II, se procederá a la aprobación del principio por mayoría de dos tercios de cada Cámara, y a la disolución inmediata de las Cortes. 2. Las Cámaras elegidas deberán ratificar la decisión y proceder al estudio del nuevo texto constitucional, que deberá ser aprobado por mayoría de dos tercios de ambas Cámaras. 3. Aprobada la reforma por las Cortes Generales, será sometida a referéndum para su ratificación

7 LAPORTA SAN MIGUEL, Francisco Javier (2004): «Las dos vías para la reforma de la Constitución», Claves de Razón Práctica, 145, pág. 21. 
za Popular mantuvo un voto particular al dictamen de la Comisión del Congreso, que abogaba por un entendimiento de la revisión total cuando «afect[ase] a más de la mitad de los artículos de la Constitución o a un título completo de la misma».

Parece correcto pensar, por tanto, que la revisión total no fue concebida durante el proceso de elaboración como una modificación de la integridad de los artículos de la Constitución, sino como una alteración sustancial de los mismos, por referirse a títulos completos o a más de la mitad de los preceptos ${ }^{8}$. En cualquier caso, la referencia a «la mitad de los preceptos» tampoco habría de ser interpretada, a nuestro juicio, de un modo literal y meramente matemático, sino que debería equipararse a una reforma de calado. De lo contrario, el debate se trasladaría a la concreción de qué debe entenderse por una afectación a más de la mitad de los artículos, teniendo en cuenta, además, que no todos los contenidos constitucionales inciden de un mismo modo sobre los principios estructurales de nuestro ordenamiento, a los que nos referiremos más adelante?.

Por lo que respecta al alcance de una eventual revisión total, nuestra Carta Magna no establece cláusulas de intangibilidad y nuestro sistema no es de democracia mili$\operatorname{tante}^{10}$, de modo que, desde el respeto a los cauces procedimentales, tendría cabida cualquier reforma constitucional, incluso cuando se afectase a los elementos definitorios de la Constitución. Sin embargo, existe un profundo debate doctrinal sobre la existencia o inexistencia de límites materiales a la reforma, «zanjado», no obstante, por nuestro Tribunal Constitucional ${ }^{11}$.

${ }^{8}$ En esta línea, GARCÍA ATANCE señala que «la reforma total excedería de la competencia limitada de la actividad revisora» y TAJADURA TEJADA advierte que «una reforma total es un oxímoron, porque toda reforma es un cambio limitado y parcial por definición». Estos autores se inclinan por la postura doctrinal que considera que una revisión total no puede concebirse como absoluta, ya que en tal caso el poder constituyente constituido se excedería en las potestades que tiene atribuidas. Vid. GARCÍA ATANCE, María Victoria (2002): Reforma y permanencia constitucional, Madrid, Centro de Estudios Políticos y Constitucionales, págs. 228 y ss. y TAJADURA TEJADA, Javier (2018): La reforma constitucional: procedimientos y límites, Madrid, Marcial Pons, pág. 113.

9 LAPORTA SAN MIGUEL ha advertido que esta cuestión evoca la paradoja de los granos de trigo, en virtud de la cual es difícil determinar cuándo estamos ante un montón de granos y cuándo deja de existir tal montón a medida que vamos sustrayéndolos. PÉREZ ROYO ha sostenido que para poder hablar de reforma total hay que tener en cuenta, además de criterios cuantitativos, otros de tipo cualitativo. Hablaríamos de «revisión total» cuando esta afecte a una institución con una importancia capital, es decir, cuya «presencia en el edificio constitucional» sea decisiva. Vid. LAPORTA SAN MIGUEL, Francisco Javier (2004): «Las dos vías para la reforma de la Constitución», Claves de Razón Práctica, 145, págs.19-20 y PÉREZ ROYO, Javier (1987): La reforma de la Constitución, Madrid, Congreso de los Diputados, págs. 194-197.

${ }^{10}$ Así lo ha sostenido el Tribunal Constitucional en reiteradas ocasiones. Por todas, STC 48/2003 (FJ7).

11 Algunos autores han considerado inmodificables determinados preceptos de la Constitución. Por ejemplo, ALZAGA VILLAAMIL ha sostenido que la unidad de España del artículo 2 CE y los derechos y libertades son límites absolutos implícitos a la reforma. En este sentido, ha señalado que estos son «los dos grandes soportes que, en la medida en que son previos a la Constitución, en algún sentido no forman parte de la misma y no pueden ser reformados». Lo mismo sucedería con la dignidad humana, 
En diversas sentencias el supremo intérprete de la Constitución deja clara su postura (por todas, SSTC 48/2003 (FJ 7), 31/2009 (FJ 13) y 41/2014 (FJ4)), señalando que no existe «un núcleo normativo inaccesible a los procedimientos de reforma constitucional». En las SSTC 103/2008 (FJ 4) y 42/2014 (FJ 4) va más allá, admitiendo que el «planteamiento de concepciones que pretendan modificar el fundamento mismo del orden constitucional tiene cabida en nuestro ordenamiento», desde el respeto a los procedimientos de reforma de la Constitución. Asimismo, en la STC 48/2003 (FJ 7) añade que «la CE, a diferencia de la francesa o la alemana, no excluye de la posibilidad de reforma ninguno de sus preceptos ni somete el poder de revisión constitucional a más límites expresos que los estrictamente formales y de procedimiento».

El TC, por tanto, excluye la existencia de cualesquiera límites, salvo los procedimentales, siendo posible cualquier tipo de reforma desde un punto de vista material, y lo hace de un modo claro y expreso que no deja lugar a dudas. En consecuencia, la reforma total no habría de adherirse necesariamente a ningún tipo de valores ni habría de respetar ninguno de los elementos decididos por el constituyente en 1978.

\section{B. Sobre la revisión parcial: la selección «geográfica» del art. 168.}

De acuerdo con Herrero y Rodríguez de Miñón, el art. 168 CE, al hacer alusión al Título preliminar, al Capítulo segundo, Sección primera del Título I y al Título II, trata de proteger las decisiones consideradas fundamentales: «el principio democrático, los derechos fundamentales, la forma monárquico-parlamentaria y el principio autonómico» ${ }^{12}$. Sin embargo, la redacción final del precepto no se ha referido a tales elementos en esos términos, y la selección se ha llevado a cabo en bloque, bien refiriéndose a títulos completos o, en el caso de los derechos fundamentales, al capítulo completo que los contiene ${ }^{13}$.

\footnotetext{
«fundamento del orden político» de acuerdo con el artículo 10 CE. Por lo que respecta a DE OTTO Y PARDO ha entendido que el verdadero límite a la reforma es la democracia, y FONDEVILA MARÓN ha defendido la existencia de «unos límites que se dan, en todo caso, de manera implícita, y que constituyen un núcleo indisponible de toda Constitución», señalando en concreto los derechos fundamentales, la forma de Gobierno, la separación de poderes, el Estado de Derecho, el principio democrático, la forma de Estado y la estructura social. Vid. ALZAGA VILLAAMIL, Oscar (2017): Comentario sistemático a la Constitución española de 1978, Madrid, Marcial Pons, pág. 739; DE OTTO Y PARDO, Ignacio (1982): Derecho Constitucional. Sistema de fuentes, Madrid, Ariel, pág. 64 y FONDEVILA MARÓN, Manuel (2015): «Los límites a la reforma de la Constitución», Anuario de Facultade de Dereito da Universidade da Coruña, 19, págs. 249-260.

12 HERRERO Y RODRÍGUEZ DE MIÑÓN, Miguel (2016): Tres conferencias sobre la reforma constitucional, Valencia, Tirant lo Blanch, pág. 24.

13 En palabras de REDONDO GARCÍA, «indudablemente no todos los asuntos que se agrupan en el art. 168 tienen la misma relevancia para el modelo constitucional y probablemente fue un error de los redactores de la Constitución introducir referencias concretas a las materias de revisión constitucional, (...) pero, lo cierto es que, a la postre, todos los contenidos incluidos en el art. 168 disfrutan de idéntica
} 
Este peculiar modo de articular su defensa para evitar su fácil modificación ha recibido grandes críticas por parte de la doctrina. Los distintos autores coinciden en la arbitrariedad con la que el constituyente optó por referirse a los pilares sistémicos del orden constitucional. Algunas cuestiones menos relevantes como las relativas a los colores de la bandera o la ubicación de la capital de España gozan de la especial protección que, de un modo textual, les brinda el art. 168, y otras partes con una enorme trascendencia como las relativas a la dignidad de la persona, la igualdad ante la ley o la jurisdicción constitucional parece que pudieran ser reformadas a través del procedimiento ordinario.

Por otro lado, la inclusión de cuestiones de detalle relacionadas con las instituciones que el constituyente trató de proteger puede llegar a convertirse, paradójicamente, en un factor que menoscabe su legitimidad. Tal ha sido el caso de la preferencia sucesoria a la Corona de los varones sobre las mujeres, cuya compatibilidad con el principio de igualdad es controvertida, y que se encuentra sustraída al procedimiento ordinario de reforma, de tal modo que el referéndum obligatorio del propio art. 168 podría interpretarse en clave plebiscitaria y entenderse que la pregunta lo es sobre la opción monárquica o republicana.

Autores como DE OTTO Y PARDO también han criticado la sobreprotección de preceptos como el que establece la autonomía universitaria o aquel que obliga a las asociaciones a inscribirse en un registro ${ }^{14}$, y DE VEGA GARCía ha señalado como inadecuada la incorporación a las materias del art. 168 cuestiones como las relativas a los símbolos autonómicos o el derecho del monarca a nombrar a los miembros de su Casa ${ }^{15}$.

Por otro lado, resulta objetable que en nuestra Constitución se haga una referencia en bloque a todos los preceptos relativos a la Corona, a diferencia de lo que sucede en ordenamientos en los que hay cláusulas de intangibilidad, en los que se protege una determinada institución, pero no todos los pormenores regulatorios que le afectan. A modo de ejemplo, el art. 89 de la Constitución Francesa de 1958 establece que «no podrá la forma republicana de gobierno ser objeto de reforma», pero sí es posible llevar a cabo modificaciones puntuales que no pongan en tela de juicio tal forma política. El hecho de que las materias reservadas se identifiquen por referencia a los títulos que las contienen impide que se lleven a cabo revisiones puntuales necesarias para revitalizar la institución y acomodarla a las exigencias que el paso del tiempo impone $^{16}$. Tal es el caso de la sucesión que, como hemos señalado, continúa otorgando

garantía normativa». En REDONDO GARCÍA, Ana María (2004): «Algunas consideraciones en torno a la anunciada Reforma Constitucional», Parlamento y Constitución: Anuario, 8, págs. 145-146.

14 DE OTTO Y PARDO, Ignacio (1987): «Derecho Constitucional. Sistema de fuentes», Madrid, Ariel, pág. 59.

15 DE VEGA GARCÍA, Pedro (1985): La reforma constitucional y la problemática del poder constituyente, Madrid, Tecnos, pág. 148 y ss.

16 TAJADURA TEJADA sostiene que el verdadero propósito subyacente al art. $168 \mathrm{CE}$ es «blindar la forma monárquica de la jefatura del Estado, pese a que, a nuestro juicio, sigue siendo reprobable la 
preferencia al varón sobre la mujer, pero cuya supresión requeriría, injustificadamente, la activación del procedimiento agravado.

TAjAdura TejAda también considera llamativa la actual selección de materias, ya que obligaría a disolver las Cortes y celebrar elecciones generales para trasladar a otra Comunidad la capital de España, pero no sería necesario hacerlo, si se atiende al tenor literal de la norma, para modificar o cercenar las funciones o composición del Tribunal Constitucional o para suprimir el Senado. Además, el mismo autor pone de manifiesto que puede activarse un procedimiento de reforma u otro en función del título al que afecten tales modificaciones. Por ejemplo, una reforma de las bases constitucionales de la organización territorial del Estado, respetando el principio autonómico, podría ser posible mediante su nueva configuración en el Título VIII, evitando realizar cambios en el Título preliminar para eludir los cauces del art. 168. Esta posibilidad de emplear uno u otro procedimiento atendiendo exclusivamente al lugar en el que se produzcan las modificaciones resulta poco coherente.

En definitiva, sería conveniente superar esta arbitrariedad a partir de una redefinición de las materias objeto de reforma agravada, para que el art. 168 CE proteja los aspectos nucleares de nuestra Constitución, pero no cuestiones menos relevantes que son dotadas de una sobreprotección injustificada.

\section{Sobre la cláusula de la afectación}

En línea con el apartado anterior, también resulta preciso poner de manifiesto que la ambigüedad del término «afectar» ${ }^{17}$ empleado en el art. $168 \mathrm{CE}$ plantea algunos problemas de interpretación:

En el plano teórico podría sostenerse que el término «afectar» puede concebirse tanto de modo directo como indirecto, es decir, la enunciación de Títulos no sería taxativa, existiendo una «vis atractiva» respecto de todos aquellos preceptos que puedan tener algún tipo de influencia sobre las partes a las que alude el art. $168 \mathrm{CE}$.

LAPORTA SAN MigueL ${ }^{\mathrm{I} 8}$ ha sostenido que se trata de una afectación completa de los títulos a los que el precepto se refiere, llegando a esa conclusión a partir de un examen de los debates constituyentes. El Tribunal Constitucional, por su parte, ha abogado por una interpretación restrictiva, pero comprendiendo todos y cada uno de los artículos insertos en los títulos «blindados» al procedimiento ordinario. Final-

técnica jurídica empleada a tal fin». CONTRERAS CASADO va más allá, y añade al uso de una «técnica jurídica lamentable» una «ceguera política incomprensible». Vid. TAJADURA TEJADA, Javier (2018): La reforma constitucional: procedimientos y límites, Madrid, Marcial Pons, págs. 115-127 y CONTRERAS CASADO, Manuel (1992): «Sobre el título X de la Constitución Española: de la reforma constitucional», Revista de derecho político, 37, pág. 310.

${ }_{17}$ Art. 168 CE: «Cuando se propusiere la revisión total de la Constitución o una parcial que afecte $(\ldots) »$.

18 LAPORTA SAN MIGUEL, Francisco Javier (2004): «Las dos vías para la reforma de la Constitución», Claves de Razón Práctica, 145, pág. 22.

(C) UNED. Revista de Derecho Politico

N. ${ }^{\circ} 108$, mayo-agosto 2020, págs. 219-246 
mente, ALÁEz CORRAL ${ }^{\mathrm{I} 9}$ aprecia la existencia de una afectación en una doble vertiente: directa, si se produce una modificación textual de alguno de los artículos insertos en los títulos mencionados en el art. 168 (arts. 1-9, 15-29, 56-65) o indirecta, por incidir sobre el contenido de algún principio estructural.

Se ha objetado a la primera de las posturas, que aboga por la interpretación extensiva del término «afectar», que podría arrastrar a la práctica totalidad de los preceptos constitucionales al mecanismo de reforma agravado, ya que los títulos de la Constitución no son compartimentos estancos, sino que, presentan interrelaciones y una coherencia sistemática. En este sentido, Punset Blanco ha sostenido que «semejante expansividad no encuentra (...) apoyatura constitucional», y añade que el poder constituido carecería de potestades para modificar el ámbito material expresamente concretado en los dos preceptos de reforma. Además, «se encuentra sometido a las predeterminaciones orgánico-procedimentales establecidas en el texto constitucional» ${ }^{20}$.

A nuestro juicio, una extensión amplísima podría dificultar al órgano rector de la Cámara la selección del procedimiento adecuado a seguir, sustentándose sus decisiones en argumentos jurídicos discutibles. Por otro lado, se le otorgarían unas potestades exorbitantes, al poder determinar discrecionalmente cual habría de ser el procedimiento adecuado de reforma. En esta línea, el TC ha sostenido en el ATC 9/2012 (FJ 2) que «admitir la pretensión de los recurrentes» [que sostenían que una reforma del art. 135 CE suponía una reforma encubierta del título preliminar] supondría «dejar a la discreción del órgano rector de la Cámara la determinación del procedimiento de reforma constitucional».

La segunda interpretación aludida, defendida por LAPORTA SAN Miguel, considera que durante la elaboración de la CE inicialmente se había propuesto una redacción que consideraba que el procedimiento agravado debería seguirse cuando la reforma afectase a un título completo. La redacción final, sin embargo, procedió a mencionar explícitamente aquellas partes en concreto que deberían ser sustraídas al procedimiento ordinario, y por eso sostiene que «la expresión afectar a, inicialmente referida a títulos completos de la Constitución», apareció finalmente para referirse a esos títulos o secciones textualmente. «Pero con ello, esa expresión [...] perdía su contexto de significación y se convertía en un problema» ${ }^{21}$.

19 ALÁEZ CORRAL, Benito (2000): Los límites materiales a la reforma de la Constitución española de 1978, Madrid, Centro de Estudios Políticos y Constitucionales, págs. 333 y ss. También BILBAO UBILLOS, REY MARTÍNEZ y VIDAL ZAPATERO consideran que «la división de materias no es puramente topográfica o numérica. Así, cualquier modificación que afecte sustancialmente a alguna de las materias del 168 [...] debe hacerse por esa vía. Lo que se protegen son los principios estructurales, no preceptos concretos». Vid. BILBAO UBILLOS, Juan María; REY MARTÍNEZ, Fernando y VIDAL ZAPATERO, José Miguel (2010): «Lecciones de Derecho Constitucional», Valladolid, Lex Nova, pág. 292.

20 PUNSET BLANCO, Ramón (2014): «Potestades normativas y forma de gobierno», Madrid, Centro de Estudios Políticos y Constitucionales, pág. 221.

${ }^{21}$ LAPORTA SAN MIGUEL, Francisco Javier (2004): «Las dos vías para la reforma de la Constitución», Claves de Razón Práctica, 145, pág. 22. 
Esta tesis, a nuestro juicio, alberga una cierta contradicción, ya que el autor se muestra crítico con la apelación a la voluntad constituyente, por considerarla poco determinante, pero en el mismo texto hace alusión al proceso de elaboración de la constitución a efectos de construir su teoría. Por otro lado, es necesario atenerse a la redacción final del precepto, no a una redacción previa al texto definitivo de la Constitución. Consciente de estas debilidades, el autor admite en último término la posibilidad de que esa afectación se extienda a todos y cada uno de los preceptos incluidos en los Títulos mencionados, pero siempre y cuando se interprete de un modo restrictivo, sin aceptar la afectación indirecta y entendiendo en consecuencia que no hay ningún precepto que deba reformarse a través del procedimiento agravado si no está encuadrado en los títulos que el artículo 168 CE explicita.

Esta última interpretación es, precisamente, la que parece haber acogido el TC, y en la Declaración 1/1992 ha dejado entrever que el artículo 168 es un precepto de aplicación restrictiva y que utiliza un criterio no extensivo, es decir, que únicamente cabe su activación cuando se abogue por reformar preceptos ubicados en el Título Preliminar, el Capítulo segundo, Sección primera del Título I o el Título II, o cuando se pretenda llevar a cabo una revisión total. Por otro lado, en el ATC 9/2012, sobre la reforma del artículo $135 \mathrm{CE}$, el TC se ha referido de un modo más contundente a la literalidad, considerando que el procedimiento agravado «está limitado por su propia naturaleza al objeto normativo en él contemplado, sin que quepa ni sea razonable una extensión por vía alguna de unos requisitos ya de por sí hiperrígidos» (FJ 2).

En coherencia con esta afirmación, las dos únicas reformas acometidas de nuestra Carta Magna, aunque podrían suponer una afectación indirecta a preceptos consagrados en las partes «blindadas» por el art. 168, han sido acometidas a través del procedimiento ordinario de reforma con el beneplácito del TC.

A nuestro juicio, la aceptación en abstracto de una interpretación extensiva conduciría a la observancia de unos requisitos excesivamente rígidos para reformar una Constitución que hasta la fecha no ha sido actualizada con la frecuencia debida. No obstante, y en contraposición, adoptar una interpretación demasiado restrictiva puede suponer un vaciamiento de contenido de las partes mencionadas si estas se modifican a través de preceptos no mencionados por el art. $168 \mathrm{CE}$ pero que mantienen una estrecha relación con los mismos.

Cabe señalar que el TC también se ha tenido que enfrentar a la misma ambigüedad terminológica en relación con los decretos-leyes, ya que el art. 86.1 CE establece que estos «no podrán afectar al ordenamiento de las instituciones básicas del estado, a los derechos, deberes y libertades de los ciudadanos regulados en el Título I (...)». Con motivo de la expropiación de la empresa Rumasa, el supremo intérprete de la Constitución tuvo la oportunidad de pronunciarse sobre esta imprecisión terminológica, ya que la utilización de esta figura normativa indudablemente suponía en este caso una afectación al derecho de propiedad consagrado en el artículo 33, inserto en el Título I. Así, en la STC 111/1983 (FJ 8) sostuvo que «el otorgamiento al verbo «afectar» de un contenido literal amplísimo [...], conduce a la inutilidad absoluta 
del Decreto-Ley, pues es difícil imaginar alguno [algún Decreto-ley] cuyo contenido no afectase a algún derecho comprendido en el Título I».

El TC, por tanto, se muestra crítico con tal extensión y apela a la necesidad de alcanzar un equilibrio de modo que dicha cláusula «debe ser entendida de modo tal que ni reduzca la nada el Decreto-Ley [...] ni permita que por Decreto-ley se regule el régimen general de los derechos, deberes y libertades del Título I, ni dé pie para que por Decreto-ley se vaya en contra del contenido o elementos esenciales de alguno de tales derechos».

Es una interpretación que, como puede apreciarse, coincide con la que parece derivarse de la jurisprudencia relativa a los procedimientos de reforma constitucional, reacia a ampliar el ámbito material más allá de la interpretación del tenor literal del art. 168 CE.

Finalmente, la última de las propuestas, aportada por AlÁEz CORRAL, se inspira en la Constitución alemana, en la que se establece una cláusula de intangibilidad ${ }^{22}$ en su artículo 79.3, que reza del siguiente modo: «No está permitida ninguna modificación de la presente Ley Fundamental que afecte la organización de la Federación en Länder, o el principio de la participación de los Länder en la legislación, o los principios enunciados en los artículos 1 y 20 ».

Para este autor, por afectación debe entenderse un «menoscabo de la esencia de los principios», y señala que así se interpretó en un asunto suscitado ante el Tribunal Constitucional Alemán en el que existía una afectación de los principios de Estado de Derecho, división de poderes o respecto a la dignidad humana» ${ }^{23}$. Para este Tribunal, la exigencia de la no afectación implica la «abstención en el menoscabo de su esencia normativa, es decir, aquellos elementos nucleares que, transformando el principio en regla, lo hacen constitucionalmente reconocible» ${ }^{24}$.

A esta misma conclusión podría llegarse en relación con el art. 168 CE, de modo no toda afectación indirecta implicase la necesidad de seguir el procedimiento agravado de reforma, sino únicamente cuando se vaciase de contenido los principios estructurales, los derechos fundamentales o los elementos esenciales atinentes a la institución monárquica.

22 Las cláusulas de intangibilidad, al igual que la reserva procedimental del art. $168 \mathrm{CE}$, cumplen con una función protectora de determinadas decisiones fundamentales consagradas normativamente en las constituciones. De hecho, las materias a las que hace alusión el art. 168 coinciden con las sustraídas al poder de reforma en las cláusulas de intangibilidad de algunas constituciones de nuestro entorno, como la francesa, la alemana o la italiana. Por lo que respecta al elemento diferenciador fundamental, cabe señalar que las cláusulas de intangibilidad suponen un límite absoluto a la reforma, mientras que la reserva procedimental del art. $168 \mathrm{CE}$ se limita a dificultarla, exigiendo un plus de consenso para alterar los elementos a los que el poder constituyente atribuye una mayor relevancia.

${ }^{23}$ BVerfGE 30, 1, 24 y ss.

24 ALÁEZ CORRAL, Benito (2000): Los límites materiales a la reforma de la Constitución española de 1978, Madrid, Centro de Estudios Políticos y Constitucionales, págs. 232-238. 


\section{POSTURAS DOCTRINALES ENFRENTADAS: REFORMA ORDINARIA VS. AUTORREFORMA}

Llegados a este punto, hemos de considerar que gran parte de las reformas constitucionales propuestas por la doctrina deberían ser llevadas a cabo siguiendo los cauces del art. $168 \mathrm{CE}^{25}$. Considerando que este precepto puede tener un efecto disuasorio debido a su complejidad y que presenta algunas ambigüedades y defectos técnicos a los que nos hemos referido anteriormente, cabe plantearse la posibilidad de que, en primer lugar, sea modificado el propio procedimiento agravado para acometer, en una segunda fase, la reforma de dichos preceptos constitucionales a través de un cauce procedimental simplificado.

Teniendo en cuenta que el «quid de la cuestión» radica en determinar cuál ha de ser el procedimiento más adecuado para modificar — valga la redundancia— el propio procedimiento agravado de reforma ${ }^{26}$, nos detendremos en el examen de las posturas doctrinales enfrentadas.

\section{A. La tesis de la idoneidad del procedimiento ordinario de reforma para modificar el art. $168 \mathrm{CE}$.}

La posibilidad de que sea el artículo 167 CE el cauce más adecuado para reformar el art. 168 CE se apoya, fundamentalmente, en la literalidad de la propia Constitución. A esta redacción se suma la interpretación restrictiva del TC.

Por lo que respecta a la doctrina, el mayor defensor de que esta modificación se lleve a cabo es LAPORTA SAN Miguel.

25 Por ejemplo, la modificación de la organización territorial del Estado, la inclusión de una referencia a la Unión Europea en el Título Preliminar, la eliminación de la discriminación en la sucesión monárquica o la modificación del catálogo de derechos fundamentales exigiría seguir los cauces procedimentales del art. $168 \mathrm{CE}$.

26 Aunque excedería del objeto de este trabajo abordarlo, es preciso señalar que existe un debate desde la lógica y la filosofía del Derecho (iniciado por ALF Ross), que considera irreformables los preceptos relativos a la reforma constitucional. Su argumentación se basa fundamentalmente en que una proposición no puede referirse a sí misma, de modo que un precepto no puede ser reformado de acuerdo con el procedimiento en él mismo establecido ya que esto conduce a una absurdidad lógica. Por otro lado, y a modo de ejemplo, no existiría una norma superior en la que fundamentase su validez un nuevo artículo $167^{\prime}$ reformado, y si se pretende fundamentar su validez en el artículo 167 originario nuevamente existe una contradicción ya que, un artículo 167' que establece un procedimiento de reforma $\mathrm{P}^{\prime}$, fundamenta su validez en un artículo 167 originario que establece que el único procedimiento de reforma válido es $\mathrm{P}$ originario. En conclusión, existe una contradicción en la inferencia lógica. Otro argumento que ha proporcionado JUAN MORESO parte de la consideración de que existe una suerte de reservas de constitución, representadas por las normas de reforma constitucional, de manera que no cabe delegar la reforma en un órgano distinto al previsto, que es lo que se sucede si se da una autorreforma. Vid. ROSS, Alf (1963): Sobre el derecho y la justicia, Buenos Aires, Eudeba, págs. $76-82$ y JUAN MORESO, José (1991): «Disposiciones de reforma constitucional», Doxa: Cuadernos de filosofía del Derecho, 10, págs. 201-222.

(C) UNED. Revista de Derecho Politico

N. ${ }^{\circ} 108$, mayo-agosto 2020, págs. 219-246 
Este autor basa su tesis en distintos argumentos ${ }^{27}$ :

La ausencia de una referencia expresa al art. 168 dentro de sus enunciados conduce a pensar, a priori, que el mecanismo adecuado para modificarlo sería el establecido en el art. 167. Por tanto, «la idea de que el art. 168 tiene que ser reformado por su propio procedimiento tiene que sustentarse en razones distintas a esa interpretación de su tenor literal» ${ }^{28} y$, no es posible llegar a la conclusión de que «la autorreforma del 168 pueda ser una consecuencia deductiva de ese precepto».

En segundo lugar, invocar la intencionalidad del constituyente para deducir que el art. $168 \mathrm{CE}$ ha de reformarse a través de sí mismo entraña el riesgo de incluir el sesgo voluntarista de quien apela a ella, «introduciendo en el razonamiento algunas de nuestras opiniones» ${ }^{29}$, es decir, invocando una supuesta voluntad originaria para, en la práctica, tratar de defender una postura propia.

En tercer lugar, la apelación a una justificación subyacente exigiría ir más allá de las reglas para introducirnos en el campo de los principios, y como el propio autor reconoce, «la cuestión es cómo identificar claramente ese propósito o fin a partir solo del texto literal que tenemos delante» ${ }^{30}$.

Por lo que respecta a la existencia de una laguna técnica, esta se daría «si no pudiera iniciarse el procedimiento de reforma, o si no existieran las cámaras, o si no se contemplara ningún procedimiento para discutir la cuestión, o si no estuviera previsto un procedimiento de ratificación». Sin embargo, en este caso «el precepto puede aplicarse sin ningún problema», no requiriéndose otro precepto para la eficacia de otros procedimientos de reforma ${ }^{31}$. En esta línea, tampoco se presentaría una laguna normativa, ya que a partir de una lectura literal es posible conocer a través de qué procedimiento habría de acometerse la reforma de los distintos preceptos.

Finalmente, tras estudiar el proceso de redacción del art. $168 \mathrm{CE}$, el autor concluye que el término «afectar» se refiere a los títulos completos a los que alude el art. $168 \mathrm{CE}$, de modo que las cuestiones de detalle o menores podrían reformarse directamente a través del procedimiento ordinario. El precepto estaría pensado, por lo tanto, para «impedir una mutación histórica de nuestro perfil político-constitucional» en ausencia de grandes consensos ${ }^{32}$.

Hemos de admitir que un argumento que refuerza la interpretación del autor es el relativo a la selección de materias ya examinada: partiendo de la actual configuración debería seguirse el mismo procedimiento para añadir un color a la bandera de España que para llevar a cabo una revisión total que modifique todo nuestro entramado institucional o los principios básicos de nuestra Constitución. No parece que

27 LAPORTA SAN MIGUEL, Francisco Javier (2004): «Las dos vías para la reforma de la Constitución», Claves de Razón Práctica, 145, págs. 14-23.

28 Ibid, pág. 16

29 Idem.

30 Ibid, pág. 17

31 Ibid, págs. 17-18

32 Ibid, pág. 23. 
fuera esta la intención al configurar un doble procedimiento de reforma, teniendo en cuenta que durante los debates constituyentes las iniciativas estaban encaminadas a proteger decisiones como la unidad del Estado, la forma de gobierno o los derechos y libertades, pero no todos y cada uno de los contenidos heterogéneos a los que se hace referencia en los Títulos explicitados en el art. 168 CE.

Por lo que respecta a las argumentaciones de otros autores, Aláez Corral ha defendido la posibilidad de reformar el artículo 168 siempre y cuando no se afecte a los «principios estructurales protegidos por el artículo $168 \mathrm{CE}$ ». Estos principios son el principio de Estado social, de Derecho, autonómico y democrático ${ }^{33}$.

También se ha señalado que el positivismo es la «única dimensión jurídicamente relevante», de modo que otros argumentos de índole filosófico, lógico o de conveniencia política no resultarían determinantes ${ }^{34}$.

La postura del Tribunal Constitucional, ya aludida con anterioridad, es restrictiva. En las dos ocasiones en las que pudo pronunciarse con motivo de las dos reformas de nuestra Constitución, rechazó la extensión de las materias a las que se refiere el artículo $168 \mathrm{CE}$ a otras distintas de las que en él se contemplan. De hecho, considera que la literalidad de la norma es clara, y que de aceptarse las interpretaciones extensivas se «alteraría el equilibrio buscado por el constituyente, corriendo el riesgo de dejar a la discreción del órgano rector de la Cámara la determinación del procedimiento de reforma constitucional» (ATC 9/2012, FJ 2). En este mismo fundamento jurídico el TC da por válida la argumentación de la Mesa del Congreso de los Diputados, que consideró que «el texto constitucional delimitó con bastante precisión las dos vías de reforma constitucional», no cabiendo una interpretación extensiva del art. 168 CE. En definitiva, la negativa a la extensión de las materias sometidas al procedimiento agravado sustenta nuevamente la postura que sostiene una ausencia de fundamento para extender dicho procedimiento al propio artículo 168.

Por otro lado, de la propia jurisprudencia constitucional puede extraerse un segundo argumento restrictivo que apela a la excepcionalidad de las mayorías cualificadas o reforzadas. Así, en relación con la exigencia de una mayoría reforzada para la aprobación de las leyes orgánicas, el supremo intérprete de la Constitución ha señalado en la STC 5/1981 (FJ 21) que «nuestra Constitución ha instaurado una democracia basada en el juego de las mayorías, previendo tan solo para supuestos tasados y excepcionales una democracia de acuerdo basada en mayorías cualificadas o reforzadas». En línea con los argumentos que hemos venido relatando, una extensión de las mayorías exigidas en el procedimiento agravado para la reforma de otros preceptos no insertos en los títulos explícitamente señalados supone otorgar a una minoría la posibilidad de evitar la reforma constitucional.

33 ALÁEZ CORRAL, Benito (2000): Los límites materiales a la reforma de la Constitución española de 1978, Madrid, Centro de Estudios Políticos y Constitucionales, págs. 333-339

34 REQUEJO PAGÉS, Juan Luis (2018): «Comentario al artículo 168», en RODRÍGUEZ PIÑERO Y BRAVO FERRER, M. y CASAS BAAMONDE, E. (dirs.) Comentarios a la Constitución Española, Madrid, Wolters Kluwer, págs. 1879-1885.

(C) UNED. Revista de Derecho Politico

N.o 108 , mayo-agosto 2020, págs. 219-246 
Finalmente, si el constituyente hubiera deseado evitar una reforma del procedimiento agravado a través del procedimiento ordinario, no hubiese existido impedimento alguno para hacer referencia explícita a esta circunstancia ${ }^{35}$, máxime teniendo en cuenta que fue advertido al respecto ${ }^{36}$.

\section{B. Posturas doctrinales en favor de la reforma del artículo $168 \mathrm{CE}$ a través del procedimiento que él mismo establece.}

El clásico SIEYÈs, en uno de sus más célebres escritos, señaló que «ninguna suerte de poder delegado puede modificar lo más mínimo las condiciones de su delegación», de modo que un poder de reforma no podrá alterar los preceptos en los que basa su competencia ${ }^{37}$.

De Vega García ${ }^{38}$ también se ha mostrado muy crítico con esta operación, aunque sus reflexiones se refieren a los ordenamientos en los que hay cláusulas de intangibilidad que tampoco se refieren a sí mismas, es decir, que tampoco proscriben su supresión por parte del poder constituyente constituido. En este sentido, y frente a quienes consideran que las cláusulas de intangibilidad son un obstáculo a la actualización constitucional, considera que tal afirmación es errónea ya que se limitan a proteger determinadas partes de la Constitución. Por otro lado, considera que las normas constitucionales no presentan idéntica jerarquía, rango y eficacia (de modo que existe una jerarquía interna en la propia Constitución) y, finalmente, que la elusión de dichas cláusulas mediante la operación doble «es una tesis que resulta tan ingeniosa como insostenible». Si el poder constituido es limitado, el poder de reforma no puede modificar o suprimir las normas «en que se reconoce y se regula su propia competencia». En consecuencia, siguiendo sus tesis el artículo 168 CE debería reformarse a través del procedimiento que él mismo establece.

La existencia de una jerarquía interna dentro de la propia constitución es defendida también por De OTTO y PARDo. En palabras del autor, «al establecerse una diferencia entre dos procedimientos, uno de los cuales permite una reforma total,

35 A modo de ejemplo, la Constitución de Bulgaria de 1991, que regula en el Capítulo IX la reforma constitucional, y que cuenta igualmente con un procedimiento doble en función de la materia, señala en su artículo 158 la necesidad de reformar los propios artículos relativos a la reforma constitucional a través del cauce más complejo.

${ }^{36}$ En la enmienda número 97, el grupo de Progresistas y Socialistas Independientes en el Senado advirtieron que «el mantenimiento de este artículo haría prácticamente imposible, en aquellas materias que contempla, la reforma de la Constitución. El procedimiento previsto en el artículo 161 ya confiere al texto constitucional una rigidez razonable. Piénsese, por otra parte, en la inutilidad de este artículo 162, pues bastaría su derogación por la vía del artículo 161 para salvar los obstáculos que opone a la reforma constitucional». (En aquel entonces la numeración no resultaba concordante con la definitiva).

37 SIEYÈS, Emmanuel (2007): Escritos y discursos sobre la revolución: ¿Qué es el tercer estado?, Madrid, Centro de Estudios Políticos y Constitucionales, pág. 132.

38 DE VEGA GARCÍA, Pedro (1985): La reforma constitucional y la problemática del poder constituyente, Madrid, Tecnos, págs. 262-267. 
parece claro que se establece también entre ellos una jerarquía lógica». Por este motivo, considera que no podría reformarse el art. 168 para aliviar su rigidez a través del procedimiento ordinario, porque «se estaría alterando la relación que subordina el art. 167 al 168 y resultaría un patente fraude del sistema de reforma» ${ }^{39}$. Sin embargo, no consideramos que existan argumentos jurídicos para sostener que dentro de una Constitución exista una especie de jerarquía interna, máxime cuando esta opera, como el autor señala, en el plano de la lógica.

Otros autores, de un modo más breve, se han limitado a señalar que la operación que estamos estudiando vulneraría el principio de soberanía popular, que ha de sortearse a través de una interpretación teleológica o que existiría un límite implícito que la proscribe. ${ }^{40}$ También se ha sostenido que resultaría contradictorio que «el art. 168 CE garantizara especialmente determinados contenidos constitucionales a través de su procedimiento superrígido, y que sin embargo no se protegiera a sí mismo [...] dej[ando] sin protección los ámbitos materiales que amparaba». Con esta operación, se ha señalado que «el art. 168 carecería de efectividad, ya que en un proyecto de reforma ordinaria se podría insertar un artículo que modificase o derogase el art. $168 \mathrm{CE} »^{41}$.

\section{UNA APORTACIÓN AL DEBATE}

\section{A. La interpretación de la cláusula de la afectación y el respeto a la Constitu- ción.}

Ante el problema de interpretación constitucional al que nos enfrentamos, hemos hecho alusión a las visiones contrapuestas entre aquellos que consideran que es necesario atender al tenor literal de la norma y quienes proponen una interpretación sistemática, apelando a la voluntad del poder constituyente o considerando que el verdadero propósito del procedimiento agravado es el de proteger las materias a las que se refiere, de modo que no puede burlarse mediante su reforma a través del procedimiento ordinario.

En segundo lugar, también hemos podido constatar que resulta clave la interpretación que se lleve a cabo del término «afectar».

Si dicha interpretación es demasiado amplia y carente de limitaciones, el art. 168 CE debería ser aplicado para la mayor parte de las reformas, ya que casi siempre se

39 DE OTTO Y PARDO, Ignacio (1987): Derecho Constitucional. Sistema de fuentes, Madrid, Ariel, págs. 65-68.

40 Vid. BILBAO UBILlOS, Juan María; REY MARTÍNEZ, Fernando y VIDAL ZAPATERO, José Miguel (2018): Lecciones de Derecho Constitucional, Madrid, Aranzadi págs. 353-354; RUIZ ROBLEDO, Agustín (2018): Compendio de Derecho Constitucional Español, Valencia, Tirant lo Blanch, pág. 76 y ÁlVAREZ CONDE, Enrique (2008): Curso de Derecho Constitucional, Madrid, Tecnos, pág. 194.

41 GAVARA DE CARA, Juan Carlos (2012): «Encuesta sobre la reforma de la Constitución», Teoría y Realidad Constitucional, 29, pág. 32.

(C) UNED. Revista de Derecho Politico

N. ${ }^{\circ} 108$, mayo-agosto 2020, págs. 219-246 
dará una cierta afectación indirecta a alguna de las partes mencionadas en el art. 168 CE.

Sin embargo, atenerse a un criterio restrictivo o «geográfico» conduciría a reformar cualquiera de los artículos incluidos en las partes mencionadas (arts. 1 al 9, 15 al 29 y 56 al 65) a través del procedimiento agravado, pero no otros con una incidencia fundamental sobre dichas partes. Por ejemplo, una reforma del Título IX podría atentar contra el Estado de Derecho si se elimina la independencia judicial.

Por lo que respecta a la afectación a títulos completos, el hecho de que una primera redacción de la norma hiciera referencia explícita a la modificación de «títulos completos», no es argumento suficiente para sostener que únicamente cabe activar el procedimiento del art. $168 \mathrm{CE}$ cuando se lleve a cabo una reforma íntegra de los títulos. Además, al igual que suscita dudas el concepto de la «revisión total», también resultaría difícil determinar cuando se produciría una revisión que afecte a un título completo.

En definitiva, consideramos posible combinar el respeto al tenor literal de la norma junto con la finalidad de la reserva procedimental del art. $168 \mathrm{CE}$. Esta postura, además de atenerse estrictamente a las previsiones constitucionales, no ignora que el art. $168 \mathrm{CE}$ trata de preservar determinadas decisiones políticas fundamentales, posteriormente juridificadas y consistentes en la creación de un Estado social y democrático de Derecho y un Estado autonómico, siendo la forma de gobierno la monarquía parlamentaria y garantizándose el reconocimiento de los derechos y libertades de los ciudadanos. La interpretación del término «afectar» que proponemos, por tanto, ha de equipararse a un menoscabo de los principios estructurales del ordenamiento. Este entendimiento no arrastra a toda la Constitución al procedimiento agravado, sino que solo habrán de reformarse a través del art. $168 \mathrm{CE}$ aquellos preceptos que menoscaben su esencia normativa.

\section{B. Reforma de la Constitución y decisiones constitucionales fundamentales.}

Antes de responder a la cuestión que es objeto de examen, es necesario hacer una somera reflexión sobre la neutralidad ideológica de nuestra constitución y la existencia o inexistencia de una serie de elementos estructurales en la Constitución de 1978.

Aunque el artículo 168 autoriza a una revisión total de la Constitución y el TC ha admitido que esta puede materializarse aún separándose totalmente de los elementos nucleares fijados en 1978, no es menos cierto que tal revisión, desde un punto de vista jurídico, impone un respeto al procedimiento de reforma.

El respeto a ese procedimiento consiste, a nuestro juicio, en el seguimiento de las previsiones constitucionales al respecto, debiendo llevarse a cabo una reforma de cualquiera de las partes incluidas en el propio artículo $168 \mathrm{CE}$ a través del propio procedimiento agravado, pero sin ignorar la finalidad perseguida por el constituyente 
y que se deduce de las propias normas: otorgar una protección adicional frente a la reforma de aquellas cuestiones consideradas elementales.

El respeto a la literalidad, por mucho que la técnica jurídica empleada para proteger tales elementos pueda resultar objetable, resulta de necesaria observancia, no resultando aceptables las interpretaciones que tratan de eludir artificiosamente el procedimiento agravado de reforma. Y, por otro lado, la finalidad de la norma no puede ser ignorada, de modo que cualquier operación que la desvirtúe no tendrá cabida si se pretende preservar la continuidad jurídica.

La afirmación de que el art. 168 CE trata de proteger una serie de principios estructurales o, empleando la terminología de CARL SCHMITT, unas «decisiones políticas fundamentales ${ }^{42}$ no contradice, por otra parte, los dos elementos consabidos en nuestro ordenamiento dada su reiteración por parte del TC: de un lado, que no estamos ante una democracia militante, por lo que no se impone una adhesión positiva a tales principios; de otro, que no existen límites implícitos a la reforma constitucional.

La posibilidad de que todas las opciones políticas puedan manifestarse dentro del sistema jurídico y puedan llegar a formar parte de la Constitución sin necesidad de que se de una adhesión positiva al ordenamiento no implica, no obstante, que la Constitución realmente presente un indiferentismo axiológico, tal y como se ha sostenido ${ }^{43}$.

Si la Constitución no otorgase una mayor relevancia a determinados elementos y no procurase su mayor protección no tendría razón de ser la existencia de una norma como el artículo $168 \mathrm{CE}$. Y, aunque puede parecer contradictorio el hecho de que ese mismo precepto autorice a una reforma total de la Constitución, de materializarse, ni siquiera sería preciso respetar los cauces procedimentales previstos, ya que una férrea voluntad de modificación de los elementos esenciales asentados en 1978, alterando las decisiones fundamentales consagradas en la Carta Magna, terminaría por imponerse existiera o no una posibilidad de «revisión» total de la Constitución.

En definitiva, la identificación de las decisiones constitucionales fundamentales que el art. $168 \mathrm{CE}$ trata de proteger, además, puede llevarse a cabo sin necesidad de acudir a elementos extrajurídicos, sino atendiendo a su concreta plasmación en nuestra Carta Magna. Y, además, dicha identificación resulta más sencilla dada la apelación durante el proceso de elaboración de la Constitución a la preservación de la unidad del Estado, los derechos y libertades de los ciudadanos o la forma monárquico-parlamentaria.

42 SCHMITT, Carl (1928): Teoría de la Constitución, Madrid, Alianza Editorial, 2015, pág. 60.

43 JIMÉNEZ CAMPO, Javier (1980): «Algunos problemas de interpretación en torno al Título X de la Constitución», Revista del Departamento de Derecho Político de la UNED, 7, pág. 84.

(C) UNED. Revista de Derecho Político

N. ${ }^{\circ} 108$, mayo-agosto 2020, págs. 219-246 


\section{La identificación de las decisiones fundamentales.}

El Tribunal Constitucional ha sostenido que «los artículos 1.2 y 2 CE proclaman mandatos esenciales de nuestro ordenamiento constitucional», a las que denomina «decisiones básicas del constituyente» (STC 128/2016, FJ 5). La infracción de estas decisiones o de estos «principios estructurales del ordenamiento» en palabras del TC, «conlleva también, inseparablemente, la de los que configuran nuestro Estado como «de derecho» y «democrático» (art. 1.1 CE)» (STC 128/2016). Por otro lado, «la Constitución no es la suma y el agregado de una multiplicidad de mandatos inconexos, sino precisamente el orden jurídico fundamental de la comunidad política, regido y orientado a su vez por la proclamación de su art. 1, en su apartado 1» (STC 2016/1992, FJ 3).

Con base en esta jurisprudencia, es preciso concluir, por tanto, que dentro del título preliminar «no todos los artículos incluidos tienen el mismo peso ni alcance como configuradores de las bases y fundamentos del sistema político y constitucional» ${ }^{44}$. Son, precisamente, los artículos que consagran el Estado Español como un Estado de Derecho, democrático y social, los que proclaman la soberanía nacional y el principio autonómico (arts. 1 y 2) los que gozan de una importancia superior.

Esta jurisprudencia constitucional es coherente, además, con la redacción del art. $168 \mathrm{CE}$, que ha dotado a estos principios de una protección adicional. Protección querida y buscada por el constituyente ya que, durante el proceso de elaboración de la Constitución, las distintas formaciones políticas trataron de otorgar un plus de protección a los «grandes capítulos esenciales de nuestra Constitución», representados por «sus principios recogidos en el título preliminar, las libertades a las que se dedica un capítulo del Título I y la forma de gobierno» ${ }^{45}$.

${ }^{4}$ RODRÍGUEZ-PIÑERO Y BRAVO FERRER, Miguel (2018): «Comentario al Título Preliminar», en RODRÍGUEZ PIÑERO Y BRAVO FERRER, M. y CASAS BAAMONDE, E. (dirs.) Comentarios a la Constitución Española, Madrid, Wolters Kluwer, págs. 1879-1885.

45 Durante el debate parlamentario en el Congreso, a raíz del cual se aprobó la redacción del art. $168 \mathrm{CE}$ que contiene actualmente la selección de los títulos a los que nos hemos referido reiteradamente, pueden extraerse dos conclusiones: la primera de ellas, que los distintos grupos parlamentarios en sus intervenciones trataron de otorgar un plus de protección a determinadas partes de la Constitución. La segunda, que tal protección se materializó tras descartar la inclusión de cláusulas de intangibilidad, por considerarlas inadecuadas. El grupo parlamentario de Unión de Centro Democrático consideró que la protección de esas partes, descartados los límites explícitos absolutos, pasaba por la inclusión de una redacción que protegiese los «grandes capítulos esenciales de nuestra Constitución». Por ese motivo, presentó una enmienda de adición que, defendida por Alzaga Villaamil, consideraba que tales capítulos estaban representados por «sus principios recogidos en el título preliminar, las libertades a las que se dedica un capítulo del Título I y la forma de gobierno». Son, como él mismo sostuvo, las partes que en otros ordenamientos como el noruego, el francés, el italiano o el alemán son protegidas a través de cláusulas de intangibilidad. Con esta redacción, por tanto, se lograba una finalidad protectora como la que otorgan dichas cláusulas, pero sin imposibilitar la reforma si, llegado el momento, existía un gran consenso para modificarlas. La defensa de esta enmienda, aprobada por 30 votos a favor y únicamente dos en contra, no tuvo como propósito, por tanto, evitar una modificación de todos y cada uno de los preceptos a los que se refería la nueva redacción del precepto, sino únicamente esos elementos esenciales 
Hechas estas precisiones, cabe admitir que la parte más controvertida de la tesis que estamos sosteniendo es la relativa al grado de afectación de tales decisiones fundamentales a través de la reforma constitucional. En cierta medida, podría llegar a sostenerse que la mayor parte de las reformas podrían tener algún tipo de incidencia directa o indirecta sobre las mismas. Pero, al igual que el TC consideró en relación con los Decretos Leyes que la incidencia sobre los elementos enunciados en el art. 86.1 CE iba a darse casi siempre, no teniendo cabida si se da «una alteración de elementos esenciales» (STC 111/1983, FJ 8), la misma interpretación debería sostenerse respecto de la afectación a tales principios esenciales. Y, por lo que respecta a los derechos fundamentales, es necesario apelar al respeto a su contenido esencial, al que se ha referido en reiteradas ocasiones el TC.

Hemos de reiterar, por último, que el respeto a estas decisiones fundamentales no implica que las admitamos como límites materiales implícitos a la reforma. Por mucho que autores como Ruipérez AlAmillo ${ }^{46}$ hayan sostenido que existen principios y valores que operan como un límite a la reforma o que el poder de revisión «carece de competencia legítima para proceder a realizar supuestos de destrucción, supresión o cambio de la Constitución», nuestra postura no se fundamenta en los contornos indefinidos en los que operan los límites materiales. Dos argumentos que ya hemos expuesto anteriormente fundamentan estas consideraciones: de un lado, que la Constitución prevé una reforma total a través del procedimiento agravado, sin excluir explícitamente la posibilidad de modificar precepto alguno; de otro, que el propio TC ha sostenido que no existe «núcleo normativo inaccesible a los procedimientos de reforma constitucional» (STC 41/2014, FJ 4).

Cualquier reforma constitucional que respete los cauces procedimentales establecidos en la Constitución es válida y, por otro lado, garantiza la continuidad jurídica por mucho que lo contenidos constitucionales sufran modificaciones hasta tal punto de convertir en irreconocible la norma reformada. Esta circunstancia puede resultar objetable ${ }^{47}$, y es una problemática que ha sido abordada por los defensores de los límites materiales implícitos a la reforma constitucional. Pero sus planteamientos tampoco están exentos de crítica y prueba de ello es la incapacidad de alcanzar un consenso respecto de la concreta delimitación de tales límites implícitos, resultando

inherentes a la naciente Constitución española. Vid. CONGRESO DE LOS DIPUTADOS (1978): Diario de Sesiones, 93, págs. 3470-3471.

46 RUIPÉREZ ALAMILLO, Javier (2012): «De la reforma constitucional y sus límites materiales. Consideraciones desde la teoría del Estado y de la Constitución».

47 Una postura contraria a la que defendemos es sostenida por FONDEVILA MARÓN, que considera que «lo que no podrá el jurista teórico-práctico [...] es justificar la reforma porque esta ha seguido los cauces formalmente establecidos [...] y no resultan, para un Derecho constitucional moderno, admisibles unas tesis [...] que dejan a los juristas tanto teóricos como prácticos en los órganos constitucionales sin armas contra las que enfrentarse a una reforma ilegítima de la Constitución llevada a cabo por el procedimiento previsto en la misma». Vid. FONDEVILA MARÓN, Manuel (2016): La reforma constitucional en España. Un ensayo de derecho constitucional como ciencia teórico-práctica, Santiago de Compostela, Andavira, pág. 95.

(C) UNED. Revista de Derecho Politico

N. ${ }^{\circ} 108$, mayo-agosto 2020, págs. 219-246 
difícilmente objetivable, especialmente cuando esta se fundamenta en elementos que no se derivan del texto de la propia Constitución.

En definitiva, las decisiones fundamentales, (no debiendo ser concebidas, a nuestro juicio, como límites materiales a la reforma), conducen a la imposibilidad de su modificación a través del poder ordinario de reforma (no así a través del propio procedimiento agravado) dada la reserva procedimental delimitada materialmente en el art. $168 \mathrm{CE}$, que debe ser entendida en los términos que hemos venido exponiendo.

\section{La variación del procedimiento según el tipo de reforma propuesta.}

Dado que las posturas doctrinales en relación con el art. 168 CE han tratado de aliviar su excesiva rigidez y de redefinir las materias a las que alude, en este apartado, y a modo ejemplificativo, trataremos de analizar las posibles modificaciones para alcanzar tales objetivos. Aunque el propósito de este trabajo es determinar cuál es el cauce procedimental más adecuado para reformar el procedimiento agravado, proponer un tipo de reforma en concreto puede facilitar la comprensión de nuestra tesis.

En esta línea, existen cuatro reformas posibles del precepto que permiten hacer frente a las deficiencias que presenta.

La primera de ellas, más radical, consistiría en suprimir el artículo $168 \mathrm{CE}$, preservándose la rigidez constitucional a través del procedimiento ordinario del art. 167 $\mathrm{CE}$, pese a que dicha eliminación plantearía dudas sobre la posibilidad o imposibilidad de acometer una «revisión total», surgiendo nuevamente debates respecto de la existencia o inexistencia de límites materiales a la reforma.

En segundo lugar, sería posible modificar el propio procedimiento (aprobación en dos legislaturas, mayoría de dos tercios en cada Cámara, referéndum preceptivo, ausencia de pronunciamiento respecto de la creación de una Comisión, etc.), preservándose una rigidez superior para las materias actualmente incluidas en el art. 168 $\mathrm{CE}$, pero menor que la actual.

Una tercera modificación posible pasaría por retocar las partes afectadas por el artículo 168, sustrayendo las menos relevantes para la estabilidad del sistema Constitucional y preservando el núcleo esencial de aquellas más determinantes. La dificultad de esta propuesta residiría en el modo de determinar qué se entiende por «núcleo esencial».

Finalmente, podría contemplarse la posibilidad de excepcionar el procedimiento agravado en situaciones de urgencia o por decisión del Parlamento, cuando la conveniencia política lo requiera. Esta original propuesta ha sido realizada por RUBIO Llorente, basándose en el Derecho comparado, argumentando que «esta técnica [...] podría incorporarse a nuestra Constitución, incluso ampliándola en la medida necesaria para corregir todos los defectos que se reprochan al criterio que en ella se sigue para delimitar el ámbito de aplicación de los dos procedimientos de reforma. Tanto el que fuerza a utilizar el procedimiento reforzado para reformas que afectan 
solo a cuestiones menores, como el que impide hacer uso de él para modificaciones que, aunque no versen sobre ninguno de los preceptos especialmente protegidos, alterarían sustancialmente la arquitectura constitucional» ${ }^{48}$.

La interpretación teleológica que estamos proponiendo junto con el respeto al tenor literal de la norma conduce a que la regulación de la reforma constitucional cobre sentido ${ }^{49}$. Una interpretación del precepto que se ciñese estrictamente a la selección realizada por el art. 168 CE podría conducir a que se vaciasen de contenido los principios que se proclaman en el Título preliminar. De nada serviría que el art. 1 CE hiciese referencia a nuestro Estado calificándolo de social y democrático de Derecho si una reforma constitucional a través del procedimiento ordinario permitiese que dichos principios perdieran su significación, por ejemplo, mediante la alteración de la composición de las Cortes, la eliminación de las elecciones democráticas, la supresión del recurso de amparo o la desfiguración del TC. La finalidad protectora de la norma no responde meramente a un criterio geográfico, pese a que las ambigüedades en su regulación pueden llevar a sostener tal consideración.

En coherencia con esta tesis, a la hora de reformar el propio procedimiento de reforma ha de preservarse la misma lógica. Por este motivo, toda modificación del art. $168 \mathrm{CE}$ ha de ser respetuosa con la finalidad de la norma, de modo que no se podrá afectar indirectamente a los principios esenciales del ordenamiento ni menoscabar el contenido esencial de los derechos fundamentales o la forma monárquico-parlamentaria. En consecuencia, no toda reforma del art. $168 \mathrm{CE}$ seguirá el mismo cauce

48 RUBIO LLORENTE, Francisco (2012): La forma del poder, Madrid, Centro de Estudios Políticos y Constitucionales, págs. 143-144. Tal propuesta se ha basado en el estudio realizado por AMÉRIGO ALONSO y JEREZ CALDERÓN, que, al examinar los procedimientos de reforma en diversas constituciones foráneas, han apreciado que en países como Finlandia es posible declarar una reforma como urgente, aumentándose la celeridad en la tramitación. RUBIO LLORENTE ha propuesto extrapolar este modo de proceder a nuestra Constitución, pudiendo emplearse incluso para hacer frente a los defectos que se le reprochan al artículo 168. De este modo, una mayoría contundente de las Cortes podría aprobar la excepción del artículo 168 para aquellas materias que hubiese que reformar rápidamente en virtud de una situación excepcional o aquellas cuya menor trascendencia justificasen la elusión de los tortuosos trámites del procedimiento agravado. Vid. AMÉRIGO ALONSO, José y JEREZ CALDERÓN, José Joaquín (2006): «El procedimiento de revisión constitucional en dos legislaturas», Revista española de Derecho Constitucional, 76, pág. 180.

49 TORRES DEL MORAL ha puesto de manifiesto las virtudes de la interpretación teleológica o finalista de la Constitución, señalando que muchas veces «nos orienta sobre el verdadero sentido de un precepto cuando, perplejos ante su dicción literal, sus antecedentes históricos y su inserción sistemática en un capítulo o título de la norma suprema, nos preguntamos qué es lo que en realidad se pretende con tal precepto». Vid. TORRES DEL MORAL, Antonio (2005): «Interpretación teleológica de la Constitución», Revista de Derecho Político, 63, pág. 13. Por su parte, el TC ha sostenido que «la Constitución no es la suma y el agregado de una multiplicidad de mandatos inconexos, sino que [...] debe resultar un sistema coherente en el que todos sus contenidos encuentren el espacio y la eficacia que el constituyente quiso otorgarles» (STC 201/1992, FJ 3).

(C) UNED. Revista de Derecho Politico

N. ${ }^{\circ} 108$, mayo-agosto 2020, págs. 219-246 
procedimental. Habrá que analizar si, con la modificación introducida, se produce una afectación a alguno de estos elementos ${ }^{50}$.

Anteriormente hemos hecho referencia a cuatro reformas posibles:

La primera de ellas, que pasa por la supresión del art. $168 \mathrm{CE}$, no podría llevarse a cabo a través del procedimiento ordinario, ya que se eludiría la finalidad protectora de la norma y los elementos esenciales consagrados en nuestra Constitución terminarían por ser reformados a través del procedimiento ordinario, no teniendo razón de ser la existencia de un procedimiento doble.

Por lo que respecta a la introducción de modificaciones procedimentales para flexibilizar el procedimiento, estas podrían consistir en: (1) la supresión del requisito de disolución de las Cortes; (2) la supresión del referéndum o de su obligatoriedad; (3) la rebaja en las mayorías requeridas para aprobar la reforma o (4) la adición de una previsión expresa a una Comisión mixta paritaria. Las dos primeras propuestas, al privar al pueblo de la posibilidad de elegir a los representantes que impulsarán y aprobarán la reforma, o al impedirles pronunciarse sobre la reforma aprobada, suponen una afectación sustancial al principio democrático. Por este motivo, el procedimiento para reformar el art. $168 \mathrm{CE}$ en estos términos habría de ser el que él mismo establece.

En cuanto a la rebaja de las mayorías requeridas para aprobar la reforma, se presentan algunas dificultades: aunque las mayorías especialmente cualificadas pueden obstaculizar las reformas, no es menos cierto que tienen, por lo general, una finalidad protectora de las minorías. Por lo tanto, habría de estudiarse con cautela la concreta reforma propuesta y su incidencia sobre los principios básicos del título preliminar y los derechos fundamentales.

Finalmente, la adición de una Comisión mixta paritaria no presenta ningún tipo de problemática para ser incluida a través de una reforma del procedimiento agravado a través del procedimiento ordinario. No se produce un atentado contra los principios consagrados en el Título preliminar, no se menoscaba un derecho fundamental ni se atenta contra la forma monárquico-parlamentaria.

${ }^{50}$ La propuesta que estamos defendiendo, aunque no sustentada en la aplicación de una interpretación literal junto con una interpretación finalista, ni basada en el estudio de los debates constituyentes, ha sido defendida por ALÁEZ CORRAL, que considera, además, que son cuatro los principios que protege el art. $168 \mathrm{CE}$ : el principio autonómico, el principio del Estado de Derecho, el principio del Estado social y el principio del Estado democrático. A su juicio, también debería emplearse el art. 168 CE para reformar el Título X si «se afectase indirectamente al contenido de alguno de los principios estructurales protegidos por el art. $168 \mathrm{CE}$ ». Por otro lado, considera que esos principios son estructurales porque, como la propia terminología pone de manifiesto, «estructuran la producción normativa». La construcción teórica de este autor no hace referencia a los derechos y libertades fundamentales ni a la forma monárquico-parlamentaria que, a nuestro juicio, deben ser incluidas como «decisiones constitucionales fundamentales», tal y como evidencian los debates constituyentes. En este sentido, vid. ALÁEZ CORRAL, Benito (2000): Los límites materiales a la reforma de la Constitución española de 1978, Madrid, Centro de Estudios Políticos y Constitucionales, págs. 333 y ss. 
La redefinición material a la que hemos aludido en tercer lugar, podría llevarse a cabo a través de la modificación del art. 168 mediante el procedimiento ordinario, siempre y cuando no se menoscaben los elementos esenciales de las partes protegidas. Así, la introducción de una reforma en el art. 168 que, en lugar de referirse a los títulos completos, señalase en concreto los preceptos que los contienen, y siempre que no se produjera una modificación textual de dichas normas, podría llevarse a cabo a través del procedimiento ordinario. A modo de ejemplo, tendría cabida una redacción similar a la que prosigue:

«Cuando se propusiere la revisión total de la Constitución o una parcial que afecte a los artículos 1, 2 y 9, que afecte a los derechos reconocidos en el Capítulo segundo, Sección primera del Título I, o que modifique la forma de gobierno, requerirá de la aprobación del principio por mayoría de dos tercios de cada Cámara, y se procederá a la disolución inmediata de las Cortes».

No resultaría objetable, como puede deducirse, una modificación que permitiese una ampliación del catálogo de derechos fundamentales, pero no sucedería lo mismo con una reforma que los cercenase, vaciase de contenido o suprimiese.

Por lo que respecta a la propuesta realizada por Rubio Llorente, esta se basaría en la adición de algún tipo de expresión que permitiese obviar el procedimiento agravado en situaciones de urgencia, o para cuestiones menores (entendiendo por tales aquellas que no pueden ser consideradas como «decisiones constitucionales fundamentales»). A nuestro juicio, si tal excepción posibilitase la modificación de los preceptos insertos en los títulos mencionados en el art. 168 CE a través del procedimiento ordinario, no tendría cabida por menoscabar la finalidad protectora del precepto.

\section{CONCLUSIONES}

Algunos autores, como hemos podido constatar, consideran que la introducción de modificaciones en el procedimiento agravado o, sencillamente, su supresión, supondría un fraude constitucional. Si el constituyente ha establecido un doble procedimiento, la posibilidad de suprimir o alterar el agravado mediante el procedimiento ordinario haría que tal diferenciación perdiese razón de ser y obligaría a incurrir en un formalismo difícilmente conciliable con una interpretación sistemática de la Constitución, cuyos preceptos no son compartimentos estancos.

Las tesis de quienes defienden la posibilidad de esta reforma de doble grado se basan en la inexistencia de tal fraude ya que, si el constituyente hubiera deseado impedirla podría haber hecho constancia a esta imposibilidad. Además, sostienen que con la reforma del art. $168 \mathrm{CE}$ a través del procedimiento ordinario lo que se hace es seguir escrupulosamente las previsiones constitucionales relativas a la reforma.

Frente a estas opiniones contrapuestas, hemos de situarnos en un punto en el que, mediante la combinación de una interpretación literal del precepto junto con una

(C) UNED. Revista de Derecho Politico

N. ${ }^{\circ} 108$, mayo-agosto 2020, págs. 219-246 
interpretación teleológica, adoptemos una postura respetuosa tanto con la letra de la norma como con su propósito. La finalidad de la norma no puede ser obviada, y a partir de un estudio de la jurisprudencia Constitucional y un examen del proceso de elaboración de la Constitución, hemos podido demostrar que lo que se pretendía con una redacción ciertamente confusa del art. 168 CE era evitar la inclusión de cláusulas de intangibilidad en nuestra norma suprema, pero otorgando una protección reforzada a los principios que figuran en el Título preliminar, los derechos y libertades de los ciudadanos y la forma de Gobierno. Principios, además, reconocidos como «rectores» o «decisiones básicas del Constituyente» por parte del TC.

Excluida la existencia de límites materiales implícitos en nuestro ordenamiento por parte del TC, y ante la posibilidad de que nuestra Constitución sea íntegramente reformada, la sobreprotección de esos principios no debe conducir, no obstante, a su consideración como límites materiales. De lo que se trata es, en realidad, de respetar la reserva procedimental por razón de la materia del art. 168 CE, cuya interpretación ha sido abordada en este trabajo.

La reforma del art. $168 \mathrm{CE}$ a través del procedimiento ordinario podrá llevarse a cabo, en definitiva, siempre y cuando no se produzca la afectación en los términos que hemos venido sosteniendo. Por ello, todas aquellas modificaciones que no menoscaben el núcleo esencial de las decisiones constitucionales fundamentales (y que no modifiquen directamente los artículos 1 al 9, 14 al 29 y 56 al 65) podrán llevarse a cabo a través del procedimiento previsto en el art. 167 CE.

A efectos de determinar cuándo se produce esa afectación sustantiva de las decisiones constitucionales fundamentales protegidas por el art. $168 \mathrm{CE}$, y para garantizar la seguridad jurídica, nos limitaremos a apuntar la conveniencia de que sea el TC el órgano encargado de esta labor. En este sentido, resultaría adecuada, por ejemplo, la inclusión de un control previo de constitucionalidad a través del cual el TC apreciase la existencia o inexistencia de un menoscabo de los principios estructurales cuando se propusiese una modificación del art. $168 \mathrm{CE}$.

Nuestra propuesta, además de no suponer un fraude a la Constitución, permite introducir modificaciones para redefinir las materias sustraídas al poder ordinario de reforma y abre la puerta a la modificación de cuestiones procedimentales (v.gr. mediante la previsión de una Comisión mixta), mejorando técnicamente el art. $168 \mathrm{CE}$. 
Title:

The modification of article 168 of the Spanish Constitution through the ordinary procedure.

\title{
Summary:
}

I. INTRODUCTION. II. THE AGGRAVATED PROCEDURE OF CONSTITUTIONAL REFORM. A. On the full review. B. On the partial review: the «geographical» selection of art. 168. C. On the affectation clause. III. DOCTRINAL DIVERGENT POSITIONS: ORDINARY REFORM VS. SELF-REFORM. A. Thesis of the suitability of the ordinary reform procedure to modify art. $168 \mathrm{CE}$. B. Doctrinal positions in favor of the reform of art. 168 through the procedure it establishes itself. IV. A CONTRIBUTION TO THE DEBATE. A. Interpretation of the affectation clause and respect for the Constitution. B. Reform of the Constitution and fundamental constitutional decisions. C. Identification of the fundamental decisions. V. THE VARIATION OF THE PROCEDURE ACCORDING TO THE TYPE OF REFORM PROPOSED. VI. CONCLUSIONS

\section{Resumen:}

La escasa activación del poder de reforma en el ordenamiento constitucional español ha sido justificada por parte de la doctrina, entre otros motivos, por la excesiva rigidez y complejidad de nuestros procedimientos de reforma, y más específicamente el consagrado en el art. 168 CE. En este trabajo reflexionamos sobre la modificación de este precepto, habida cuenta de la existencia de un debate clásico acerca del procedimiento más adecuado para acometer dicha labor. Más específicamente, planteamos la posibilidad de que, en determinadas ocasiones, su reforma se lleve a cabo a través de la técnica procedimental prevista en el art. 167 CE. Nuestra propuesta, basada en una interpretación literal del precepto combinada con una interpretación teleológica nos permite, de un lado, preservar el respeto hacia el tenor literal de la norma y, de otro, tener presente la finalidad con la que esta fue incorporada en nuestra Constitución.

\begin{abstract}
:
The low activation of the reform power in the Spanish constitutional order has been justified by the doctrine, among other reasons, by the excessive rigidity and complexity of our reform procedures, and more particularly the one enshrined in art. 168. In this work we reflect upon the modification of this precept, given the existence of a classic debate about the most appropriate procedure to undertake this task. More specifically, we raise the possibility that, on certain occasions, its reform could be carried out through the procedural technique provided for in art. 167 of the Spanish Constitution. Our proposal, based on a literal interpretation of the precept
\end{abstract}

(C) UNED. Revista de Derecho Politico

N. ${ }^{\circ} 108$, mayo-agosto 2020, págs. 219-246 
combined with a teleological interpretation allows us, on the one hand, to preserve respect for the wording of the norm and, on the other hand, to keep in mind the purpose with which it was incorporated into our Constitution.

Palabras clave:

reforma, procedimiento, fraude, interpretación.

Key words:

amendment, procedure, fraud, interpretation. 